\title{
Chapter 14 \\ A Passion for Science: Addressing the Role of Emotions in Identities of Biologists
}

\author{
Sarah M. Schönbauer
}

\subsection{Scientists and Their Profession: An Emotional Relationship}

An emotional charge of science as a profession is and has been a characteristic of living and working in the academe. Reflections on the role of the scientist have focused on emotions for a long time. Weber (1918/1946) proposed that the scientist is necessarily passionate and deeply involved in scientific life and work and must not be distracted by other more worldly matters. He argued that scientists need their passion in order to concentrate on their work as 'if the fate of their soul' would depend on it. Without passion, the scientist would lack a calling in science: being a scientist does not resemble a job but a vocation. In his famous book The Protestant Ethic and the Spirit of Capitalism, Weber (1905/1930) further depicts 'calling' as historically evolved and productive for a capitalist rationality in which some succeed and some do not. Thereby, success would actually show whether one is following ones' appropriate vocation. In Weber's conception, success, commitment, and dedication appear to be indispensable for passionate scientists that have found their vocation. An 'ideal' passionate scientist is envisioned as embracing love and affection for science while being committed to hard and enduring work. This imagination is, however, built along the tension between a scientist who is expected to produce 'objective' knowledge while being emotionally committed to the profession. Taking up this tension, Pickersgill (2012) has argued, for example, that scientific work and emotions are being co-produced. In a similar vein, Des Fitzgerald (2013) has stated that rather than seeing scientific work, affect, and emotions as

\footnotetext{
S. M. Schönbauer $(\bowtie)$

Munich Center for Technology in Society, Technical University of Munich, Munich, Germany e-mail: sarah.schoenbauer@tum.de 
distinct from scientific subjectivity, it is more important to re-think these terms as entangled.

Scientists not only acquire the skills and know-how of the job but also become part of 'an emotionally toned complex of rules, prescriptions, mores, beliefs, values, and presuppositions' (Merton 1973, p. 258). Thus, further studies have declared emotions as an 'unavoidable and essential aspect of science in all of its phases, and underlying the social basis of science itself' (Barbalet 2002, p. 134). Hence, aside from explicit training, one learns how to be a scientist while becoming part of a scientific community. In this vein, the study by Koppman et al. (2015) stated that a deep emotional commitment as counter-norm to a distanced standpoint would serve to 'orient and guide the work' of scientists (p. 33). In their work, the authors find emotional expressions of scientists to be context-dependent and specific to 'feeling styles' of research cultures and disciplines. Moreover, Mitroff (1974) and Collins (1998) showed that researchers' commitments and emotional involvements are essential for how they produce knowledge. Parker and Hackett (2012) described how researchers bonded together and stated that this involvement contributed to an increase in scientific productivity and cohesiveness. These and other empirical studies present salient examples of how emotions pervade every aspects of academic life.

Yet emotional relationships - specifically, the concept of passionate work-have also been shown to serve specific purposes. Passionate work might be regarded, for example, as a disciplinary mechanism that follows a logic of distinction, such as when the scientists who correspond to an ideal of a passionate worker are provided with symbolic capital that in turn helps to build a career in science. Such an ideal simultaneously excludes those who fail to meet the respective demands. This process has been described as a predominantly gendered one (e.g. Beaufaÿs 2015; Cech and Blair-Loy 2014), producing an academic ideal mostly as a worker 'whose life centres on his full-time, life-long job', leaving aside care responsibilities for a family (Acker 1990, p. 149). Furthermore, passionate work might also provide 'a compelling status justification (and also a disciplinary mechanism) for tolerating not just uncertainty and self-exploitation but also for staying (unprofitably)' in specific sectors (McRobbie 2004, p. 132).

This resonates with recent developments in academia, e.g. in the biosciences, making it increasingly important to analyse the emotional relationship that scientists have with their profession and work. Working in the biosciences nowadays means to be dependent on short-term contracts and funding possibilities based on competitive allocation (Slaughter and Leslie 1999; Hackett 1990). These circumstances create precarious environments for scientists (Laufenberg et al. 2018) who must then deploy coping strategies in order to manoeuvre insecurities and become a part of the exceedingly small number of scientists who make it to a stable job (Sigl 2016). At the same time, formal demands increasingly frame these work environments. This is expressed by the key currencies that scientists have to reach for, such as highly ranked publications, third-party funding, and international mobility. In a regime of uncertainty, scientists must constantly adapt their identity because they are on the move from one research group to another while engaging in research based on 
temporary funding and anticipating the need for future resources. Striving for stability and constructing a secure identity thus constitutes a major challenge for a life in science and is difficult to achieve. Ylijoki and Ursin (2015), for example, depict identities of scientists in today's transforming university environments within eight different narratives, spanning the diverse positions that scientists hold, such as rebel, loser, winner, and mobile careerist. In this work, they state that all these narratives co-exist, although with fundamentally different diagnoses of the academic environment, either regarding it as an exploitative or as an ideal institution.

Against the background of identities that 'are constructed in the midst of change and permanence' and 'linked to structural changes' (Hakala 2009, p. 177), I ask: what role does passion have in scientists' narratives? And how does this play out in researchers' identities? Or in other words, I analyse how scientists narrate passionate tales and how these tales create reference frames for their identity as scientists. I argue that this is ever more important considering the need for stability and coherence when living and working as a scientist. Accordingly, I explore how biologists recount their past and present in relation to their identity: for example, referencing their early career stage as they recall their fascination with science and striving for a career or imagining a future generation of scientists.

In so doing, I analyse the role of these narratives for the creation of selfunderstanding by group leaders and senior postdocs in the field of biology and how this self-understanding is used to create a reference frame for a future generation. I mostly draw on 11 biographical interviews with group leaders and senior postdocs as well as numerous informal conversations that were held as part of two ethnographic field studies conducted in the United States and Austria in 2013. The interviews were structured to follow the scientists' biographical stories and included questions concerning their past, present, and future in science. After extensive coding and memo writing (Charmaz 2006), I decided to explicitly focus on the scientists' emotional engagement with their profession since relating to their community by 'associating emotional states with certain activities' (Traweek 1988, p. 76) turned out to be one of the core concerns of the researchers for their lives in science.

Specifically, I analyse the scientists' stories of the past as productive for a particular rationale and storyline of their identity bringing forth qualities of a 'passionate' scientist. By recounting their past in science, the group leaders and senior postdocs I interviewed wistfully looked back at their time of initiation and early career stages while formulating concerns about the younger generation. I am not, however, inclined to analyse how scientists narrate their passionate past as potentially better or as 'golden' times in which they had more time and freedom to follow their interests (Holden 2015). Instead, I understand the scientists' tales of the past as indicating the norms, morals, and shared beliefs of a scientific community.

Accordingly, analysing these stories provides understanding of how members of a community build an identity and adhere to its culture and of how the past is formative for the scientist's identity (Traweek 1988). On the one hand, I show how the scientists create passionate tales that stabilise their identities. This is not to say that their identities become fixed but rather that emotional involvement provides a 
steadiness for how the group leaders and postdocs build their identity. On the other hand, I argue that tales of a passionate past are important for the ordering of scientific communities; their individual biographical tales not only follow a trajectory but also relate to institutional and cultural orders (Garforth and Červinková 2009). In this regard, I see scientists and their passionate tales as embedded in the social and cultural prerequisites that shape and sustain the science field (Beaufaÿs 2015). Accordingly, these tales not only represent individual experiences but show how an emotional relationship to the science profession provides an exclusive belonging. Thus, passionate tales serve to create and maintain a powerful disciplinary ideal, which is especially salient today as scientists are living and working in instable employment relationships.

Consequently, I provide a jigsaw piece for understanding further how scientists build their identities and how these identities mirror today's science cultures and their demanding environments. In the following section, I will first sketch my analytical understanding of the scientists' narratives of the past and the role of 'passion' therein.

\subsubsection{Passionate Tales}

In the stages of a scientific career, scientists learn how to craft their careers and develop culturally accepted ways of expressing emotions and feelings. A common 'emotional culture' with a specific 'feeling style' is built (Parker and Hackett 2012) that creates a collective cultural reference frame for the scientists' beliefs and feelings.

In this section, I concentrate on 'passion' as an emotional relationship between scientists and their profession that serves as a vantage point for understanding identity creation. Etymologically, passion ranges in meaning from the Latin word passio and its translation as physical suffering related to Christ's tale of woe to passion as an affect, an emotional relation with and to something. Hence, passion has a wide range - from its dual meaning of sacrifice and suffering versus love and affect and beyond to passion as an uncontrollable emotion. ${ }^{1}$ In this paper, I take passion as an emotional state that creates a basis for the scientists' fascination with science, for their spatio-temporal commitment, and for an imagination of future scientists. Moreover, using narratives of biologists, I show how a specific 'scientific passion' is made up and how this can be characterised as the scientists' emotional relationship with the science profession and with their work.

In science, passion is expressed in, for example, stories about the scientists 'burning' interest, which depict how researchers immerse themselves into their

\footnotetext{
${ }^{1}$ Passion. (n.d.). In Merriam-Webster. Retrieved from https://www.merriam-webster.com/ dictionary/passion; Passion. (n.d.). In Oxford Living Dictionaries. Retrieved from https://en. oxforddictionaries.com/definition/passion
} 
professional lives while losing track of time and having fun. 'Burning' is also part of Daston's work (2003) on the scientific persona in which she argues that many stories-literary or real-portray scientists as being obsessive. Following Daston, the scientific persona represents a collective identity that does not necessarily have to account for every scientist's individual identity; rather, it is exemplary of the particularities, modes of life, and the bodily dispositions of a group that claims this identity.

Others have portrayed scientists as being passionate in the 'flow' of doing research, which refers to a 'heightened consciousness, sharpened attention, and total immersion in the task at hand' (Parker and Hackett 2012, p. 24, referring to Csikszentmihalyi 1996). The 'flow' is best demonstrated by musicians who lose track of time and space while playing music and become fully immersed in their play. Similarly, Neumann (2006) draws on the conception of 'flow' to define her understanding of 'passionate thought'. Her concept draws attention to the creative and emotional work of researchers, occurring in their present life as well as within memories of the past. She argues that a passionate experience does not only occur in adulthood or professional instances but might also date back, for example, to childhood experiences. Additionally, she characterises a passionate experience as an interactive moment that is shared with others, drawing attention to social interaction and relationships between people. In a similar fashion, I focus on passion as individual memory of the past and as interactive experience between biologists.

Instead of focussing on passion as 'flow', I concentrate on passion as a 'drive' that leads to the scientists' self-expression as scientists showing their commitment vis-à-vis the insecurities of today's science cultures. This passionate drive appears in recollections of their initial fascination with and motivations to pursue science as well as their enthusiasm for and commitment to work. In line with this, my conception of passion is tied to emotional commitment. Koppman et al. (2015) suspect that emotional commitment is especially prominent in the early career stage. This is consistent with the passionate tales that refer to the group leaders' and postdocs' early engagements with biology. They recall those in a reminiscent mood as they account for fun, commitment, and devotion. The mode of commitment also changes with the respective career stages of the scientists, such as when initial enthusiasm and fascination develops into an affective relation with the job, which allows the scientists to cope with temporal and spatial sacrifices. Commitment also plays an important role in managing 'insecurity over one's research', 'isolation', and 'negative evaluations' (Parker and Hackett 2014, p. 555). Consequently, passion also manages instabilities, and Gill (2010) has argued that being passionately attached to work provides a disciplinary mechanism for coping with prevalent insecurities in academia. On another note, the scientific 'drive' has also been shown to provide an exclusive mechanism, discriminating between those who work along such a 'drive' and those who fail to do so (Beaufaÿs 2003).

As the scientists narrate their past and present while imagining a future generation, they create a passion narrative that provides them with meaning and selfunderstanding. This narrative allows them to master their identities and accomplish reflexive control (Giddens 1991). Moreover, I regard the passion narrative as 
organised by a particular 'plot' that serves as an overarching theme, providing an 'intelligible whole that governs a succession of events in any story' (Ricoeur 1980, p. 171). Accordingly, the successive events are transformed into a story that makes them concordant elements of the stories' plots. The scientists move back and forth in time within these plots and make them congruent in their narratives. Hence, I argue that passionate tales provide identities with self-consistency and introduce a temporal relationship in the scientists' lives. The scientists then construct identities based on a past that follows a coherent storyline while also connecting to their profession and professional values.

At the same time, the plot represents the story of a culture that is filled with tales about success and heroism of the past, providing ground for the socialisation of future scientists (Traweek 1988; Law 1994). The scientists create an identity that resembles the cultural values and myths of a specific community and culture, which also defines what is good, bad, or worthless (Ylijoki and Ursin 2015; Schönbauer 2018). Accordingly, I regard passionate stories as evolving 'as a product of certain power structures' and at times also as functioning 'to produce, maintain and reproduce those power structures' (Mumby 1987, p. 113). Yet narratives also help the scientists to orient themselves in changing environments (Ylijoki and Ursin 2015). I thus argue, that the scientists gain stability in and for their identities as they connect past and present accounts of their lives while at the same time accommodating disciplinary ideals.

For the subsequent empirical section of this chapter, I have divided my analyses into three parts, focussing on the scientists' fascination with scientific research, their early career phase, and how they imagine future scientists.

\subsection{Narrating Passionate Tales}

\subsubsection{A Fascination with Science}

When describing their biographies, the group leaders and postdocs I interviewed narrated how their paths in science unfolded. The scientists recount a continuous fascination that bridges their present and past experiences (Neumann 2006). This fascination drives the love and appreciation for a profession that fosters their exploring and discovering selves. Following Neumann, I show how stories about the past often comprise a desire to do research on a particular subject or to do research as a practice. I also depict how this fascination creates a basis for scientists' self-understanding when reflecting back on earlier times.

Remembering certain times in their lives, the scientists recall an initial interest in scientific practice that makes them able to relate parts of their lives. By drawing on childhood experiences or remembering their graduate selves, the interviewees 
narrated the developing trajectory of their career and their fascination with scientific practice leading them to where they are now: ${ }^{2}$

So I don't know quite where science came from for me [laughs]. But I have always been kind of very interested in very, like, kind of observational [tasks] and wanted to know a lot about just, like, the stuff around me, you know. (Daniel, postdoc) ${ }^{3}$

Having a working-class background, Daniel did not see the professional affiliation as something inherited from his parents. Yet he assumed that his interest in science had a specific location and origin, such as an inspirational teacher. Others tell similar stories of origin. For instance, a group leader referred to his dead grandfather telling him what to do and leading him to a career in science. While Daniel initially lacked a clear-cut origin based on a social interaction, he later on explained that he discovered how 'research was a thing' and something that one can actually do. To find out if research would be something for him, he explained that he took a year off before entering graduate school, which made him realise that he 'was born to do this' (science) while figuring out what he was not born to do. In his reasoning, he was able to tie his childhood interest in creative and explorative work to his later decision to follow a career in science.

Daniel's story is similar to other narratives that reference the urge to explore and discover the unknown. During her undergraduate studies in engineering, Abigail remembered that she was attracted to science while she was a part-time technician and doing maintenance lab work:

It was always very exciting, everything was unknown, everything was new ... You come to work with the feeling of 'ok today I might really figure out something that would not have been known before'... . You know, research is accumulation so you learn, you try, you fail, you go to other people, you discuss your ideas. And eventually after this process, you can come up with a solution or conclusion or knowledge that was not there before. Could be little change in our lives, it could be big change in our lives. So that's the drive that I felt, you know it was my calling if it is [laughs] a proper thing to say. (Abigail, postdoc)

Similar to Daniel, Abigail stated that she had always been inclined to discover the unknown and aimed to understand and develop unique innovative knowledge. But instead of tracing it back to her childhood, Abigail mentioned her encouraging supervisors in the time of her studies. She continued saying that science can be a frustrating experience because of the demands to publish and cases in which experiments do not work. Yet the memory of her former self as a graduate student and her enthusiasm for discovery provides her with a past that connects her 'calling' to her present self. The enthusiasm is still valid today and relates her emotional affection for scientific work to the profession she is working in. This is tangible as she is continuously fascinated with the ability to explore unknown frontiers and to feel the 'drive' towards this fascination, which she mentions as her calling.

\footnotetext{
${ }^{2}$ It is important to note that while the initial passion for scientific work or for a particular subject was often reflectively based on childhood experiences and interests, the decision to become a professional scientist was usually made later on during (under)graduate studies.

${ }^{3}$ All names of the quoted researchers are pseudonyms.
} 
Another example of how scientists narrate their fascination with the profession is when they remember particular subjects or fields of study that serve 'as the primary sites' of their passion (Neumann 2006, p. 406). For example, Jonas, a department leader in Austria, started to tell his story as an intentional decision to avoid everything that would have been related to industry, an 'emotional' decision rather than a 'scientific' choice. By rejecting the corporate world in favour of basic research, he expressed his appreciation of and care for nature:

I like nature and I have a close relation to nature and this is quite emotional. Not so scientific. I feel very good outdoors and I am able to calm down there. So I love nature. And this is what inspired me then in my studies to understand nature. (Jonas, department leader)

As Jonas narrated his relation to nature, his emotional experience became connected to his initial fascination with nature. Jonas, however, not only talked about this relationship when referencing the present but also when remembering his childhood. He continued to explain that as a child he liked to play at the beach and rescue fish and other sea animals from tide pools. While he stated that he had not been aware of his inclination to the natural sciences at first, he has always been fond of and inspired by nature. Jonas intentionally expressed his initial interest in fish, animals, or-more generally_nature as an emotional relationship to and interest in a subject. As a present day biologist, this interest has evolved throughout his career and now connects his childhood experience to his present life and success as a scientist. This appreciation of and passion for a subject was present especially in tales of biologists who aimed to avoid working with particular applications, such as those deployed in pharmaceutical companies.

Similarly, Sophia, a group leader, talked about her entry into science when she was 'just interested in soil science, in biology, in stuff'. She recalled that after she completed her bachelor's degree, she looked for jobs related to biology. While she stated that she was disappointed by the possibilities in the pharmaceutical sector, she also did not want to participate in 'selling agricultural chemicals', which she opposed as a scientist with environmental concerns. This reasoning was mentioned prominently in other tales of the past too, such as when a scientist stated his aversion to working as a pharmaceutical sales representative. Hence, Sophia and Jonas both expressed their passion for research on a subject, such as 'nature' or more specifically 'soil', and thereby tie their passion to earlier experiences as a child or as a graduate student when they first realised this inclination.

To conclude, the scientists remember childhood or graduate studies experiences as their entry into the profession and thereby create continuity as they follow their fascination with and motivation for pursuing a career in science. This creates a storyline that is situated in the past and related to the present, allowing for 'longer narratives of related lifetime experiences' (Neumann 2006, p. 411). Their passion for science reveals their identity as grounded in a past experience that reflects a strong inclination towards a subject or towards a practice that they have followed throughout their lives. Thus, the scientists build an identity that follows their initial fascination and 'calling', providing them with a consistent storyline. This identity 
becomes manifest when, for example, the group leaders and postdocs treated science first and foremost not as a job but as something that had always been there, that they had always felt passionate about, and that needed to be discovered. The calling represents a way for the researchers to distance themselves from an imagination that does not cohere with their expectations of working as a scientist (for some this is evident in the case of the pharmaceutical industry). This calling also coincides with an 'ideal scientist' who has always been fascinated with science and can trace passion back in time, which also means that the scientists conform to social and cultural expectations of the science field.

\subsubsection{Committing to Science}

Moving (internationally) from one laboratory to the other (e.g. Kerr and LorenzMeyer 2009) or being dedicated to scientific work around-the-clock (e.g. Garforth and Červinková 2009) are essential characteristics of the life of a scientist. As the researchers tell stories about their first experiences as professional scientists-such as during the late $\mathrm{PhD}$ phase, a junior postdoc, or the subsequent entry to the group leader phase-they account for their passion for a life in science through increasing temporal and spatial commitment to the profession. In this part, I focus on commitment as having a spatial dimension, when moving (internationally) from one laboratory to the other, and a temporal dimension, when working without temporal limitation.

Many scientists narrated moving as an essential element of their scientific career. Changing places most often represents a step forward in a career, such as when a postdoc position or professorship is offered at a new location. The researchers either moved with their research groups (as PhD students or postdocs) or relocated for a job to another university. As it is an integral part of their lives, the scientists spoke elaborately about moving.

For example, Sophia, a group leader in the US, regarded moving as 'an adventure'. She recalled that her journey started with different locations in the US and a postdoc in Stockholm and found a temporary ending upon returning to the US. She recounted her travels for scientific projects and meeting collaborators in 'exotic locations', such as when she was 'wining and dining' in a castle in Scotland while working 'really hard'. In short, and like many others, Sophia spent her early career moving. In so doing, she was rewarded with a wide scientific network across Europe and the US and enjoyed an exciting time. While moving internationally was an investment in her career, it also meant that she had to leave places that she had adapted to in order to seize opportunities somewhere else. Thus, an identity is expressed that builds on Sophia's commitment to move. In a similar vein, other scientists state the importance of moving for the sake of their CVs and giving up the spatial freedom of moving to a place of choice in exchange for relying on places that have a high reputation and visibility in their field. 
The importance of different locations is also tangible when Camilla, an assistant professor, recalled her time as a graduate student. This period of her life was filled with abundant fieldwork trips to different areas, such as Barbados, the Caribbean, San Francisco, Santa Cruz, and Hawaii. Constantly moving led her to thank Fedex as part of her thesis - they shipped her samples from one place to the other and were 'fantastic because they were on time [laughs]'. She declared that she enjoyed travelling before having a family as 'it was one of those times'. This portrayal also calls to mind an ideal worker who is fully immersed in a scientific life, changing this habit only later after starting a family and having reached a relatively secure position as assistant professor. Hence, the spatial commitment allows for the creation of distinct phases in a professional career: a phase characterised by flexibility and a phase which allows for continuity. As part of the first phase, Camilla remembered a busy time full of enthusiasm for doing what she loves. Doing fieldwork or being enthusiastic about fieldwork is often acknowledged as a space of release and enjoyment in the biosciences in contrast to the exhausting and manual-labour intensive times in the laboratory. Similar to Sophia, Camilla's self-understanding as a biologist who is devoted to fieldwork emerged together with her commitment to move from one place to the other and conduct research in different areas of the world.

Moreover, Camilla's passion for fieldwork and for the subject of her study also relates to a specific set of skills that enabled her to be 'very adaptable to new situations'. Such skills are key for scientists as they have to show adaptability. For example, Abigail, a postdoc, explained that to 'function anywhere in any working culture' and to be flexible 'enough' to fit in is important for her. Many interviewees emphasised that their moving experience was exciting and spurred their enthusiasm for a life in science. At the same time, researchers also described these times in their early career phase as exhausting and without scope for respite or staying long in one place. Accordingly, flexibility and adaptability are part of the requirements for progressing in a career and thus demarcate characteristics of a powerful scientific ideal that enables a self-regime in which scientists are individually responsible for their commitment. Hence, in line with Gill's interpretation of passionate work (2010), expressing the enjoyment of moving also indicates an underlying tolerance of the demands of a life in science and bearing its uncertainties, such as not knowing where the next position will be found.

In addition to spatial commitments, scientists talked a lot about temporal dedication to their scientific work. The interviewed biologists commonly did not associate their work with an explicit 9-to-5 routine but rather with working late and on weekends. Their tales about time ranged from the $\mathrm{PhD}$ phase to professor level onwards and most often ascribed a lack of temporal boundaries to a specific time of the past-the early career stage:

I mean I really cannot think of myself as I was working for my $\mathrm{PhD}$, actually. I used to be in the lab 16 hours. No problem. I don't think that I have it in me anymore [laughs]. (Abigail, postdoc) 
So this postdoc time is still stuck in my bones. And I still remember [this time] now, also because you know that this is sort of the point where it is revealed, the next step [a group leader position]. (Marie, group leader)

Such stories about missing temporal boundaries are abundant and often similar, such as when talking about 'these times' when you are 'all in' (Jonas, department leader). Abigail and Marie described this early career period as graduate students or postdocs as time-intensive and physically exhausting. Marie added that when she worked at Stanford University, the laboratory was always busy, even in the middle of the night when she finished her work at 2 a.m. and on weekends. This timeintensive work is not limited to but characteristic of work in a laboratory since 'bench work' most often means gruelling manual labour on graduate and postdoctoral levels. Hence, I argue that the scientists' narratives of temporal dedication to their work in the early career phase provide an explanation for and legitimisation of their present position and career, which has an impact on their self-understanding as scientists in a specific position. Thereby, the next step-a group leader positioncan be reached. This temporal commitment spurs an individualised self-regime in which the scientists are responsible for their career progress through demonstrating that they follow the demands of a powerful ideal: a scientist who never stops working.

In other narratives, I found explicit references to playful relationships and social interactions at work that were formative for the scientists' in the stages of their career. Through sharing fun and experiencing joy, the scientists become emotionally committed - not necessarily to research as a practice or as a subject but as a social endeavour. For example, Felix, a group leader, described playing volleyball in the afternoon before returning to work in the evening, as well as drinking gin and tonic together with colleagues when they finished work early:

We did a lot ... there was practically no time, day or night, when there was nobody in the lab... Instead [of working at the bench] we were playing volleyball all together on the lawn in the afternoon. Or we sometimes, if something happened, then it was ... I don't know ... [we] finished in the early afternoon and everybody was drinking gin and tonic. (Felix, group leader)

In Felix's recollections, these earlier periods seem bound to a communality that he shared with others. He noted that everybody was experiencing similar circumstances as they would invest long hours in their work, which was specific but not limited to laboratory work. They would spend weekends and nights together as they worked on their experiments. In addition to dedicating time to work, they also shared playful engagements, such as drinking gin and tonic, playing volleyball before going back to work, or celebrating achievements together.

In his current position, Felix draws on these previous experiences when arranging 'social meetings' for his group, allowing members to devote time to informal interaction. While person-to-person relationships have been described as fuelling the scientists' passion in terms of knowledge production and ideas (Neumann 2006), the social interactions that I depict here demarcate a playful relationship with the environment in which scientists make themselves at home, thereby eliding the 
distinction between work and play or private and professional personae. This also means that interacting with others makes them more likely to tolerate long work hours and demanding labour.

In these stories, the group leaders and postdocs describe their commitment as a prominent characteristic in their early careers in science. In formulating specific demands for their lives, such as spatial and temporal dedication, they foster an emotional relationship between them and their profession. Aside from periods of hard work, they also recall times of enthusiasm and joy. These emotions provide the basis for their present self-identity as scientists who (successfully) established a career. The strong sense of commitment also provides the scientists with the potential to cope with insecurities (Parker and Hackett 2014), such as when they declare exhausting times to be 'fun' and exciting when moving from one place to another or when spending day and night in the laboratory. The related identity is fragile, however, as is evident when one is 'unable to be a good role model' any longer (Felix, group leader) because one cannot be in the lab day and night and start a family at the same time. Or when Emma, a staff scientist in the US, mentioned that she 'was never a 100 per cent scientist' as she could not simultaneously care for her child and take advantage of the time after her 'sexy paper' came out by working all night. This is also evidenced in studies that show how scientists who reduce their work hours are stigmatised as not fulfilling the characteristics of an ideal worker (e.g. Cech and Blair-Loy 2014). These deviations highlight what is imagined as the norm for an identity as a scientist: a 'drive' towards scientific work and life without any spatial or temporal boundaries.

\subsubsection{Imagining a Future Generation of Scientists}

Subsequent to the scientists' commitment in their early career stages, past experiences were also used to explicitly address the demands of the profession for students and nascent scientists. Thus, I now focus on how scientists position future scientists when reproducing the past (Garforth and Červinková 2009). In these attempts to imagine a future life in science, I stress how scientists formulate necessary requirements for students and how they articulate what makes a 'good scientist' (Traweek 1988) while discussing how both are entangled with their own stories of the past.

Some biologists regarded passion as an essential quality of a scientist and specified an explicit reference frame for this quality based on their own selfunderstanding as scientists. Jonas, for example, stated that the students would not necessarily have to abandon their life outside the lab. Yet he demands that they demonstrate their passion and enthusiasm for and commitment to the job:

But ... of course you can have a relationship, it is not about that. It is about the passion. I do have ... of course the relationship is important ... it doesn't mean that you have to be there 24 hours, 7 days a week ... but this is your thing. Your passion. (Jonas, department leader) 
Consequently, passion should be expressed in an appropriate time frame as the students should not waste their time on things that are 'not important'. Jonas continued with what he misses in his own students by reflecting on a specific spirit and time during which a scientist would have to give 'a hundred percent' in order to live and work in academia:

But I think at the beginning I miss—not from everybody — I miss the absolute passion from many [students]. [Working] on weekends too, and so on. Not because I find it important to put them under pressure but as a sign that they will be head over heels for a while. It's only really fun if you are all in. Everything in life is. I have always done everything a hundred per cent. (Jonas, department leader)

This imagination of fun and excitement was entangled with his own past experience: Jonas remembered that he had always been inclined to experience everything to its fullest. When remembering his entry into science, Jonas stated that he was a 'punk' with long blue-dyed hair who was developing an ambition for challenge as he experienced his transformation from 'freak to wunderkind'. At the same time, Jonas missed an 'absolute passion' from his students, which he understood as a sign of devoting oneself to science and embracing its fun character. Accordingly, his selfunderstanding featured an assertiveness that distinguished him from others but also demonstrated a devotion to progressing his scientific self.

In a similar vein, another group leader explained her selection criteria for young scientists. For Sophia, students would not only need to be eager and intelligent but also show that they are dedicated to science by working all night:

The main thing with students for me at that time was that they are really excited. And enthusiastic. Of course, intelligent and all that kind of stuff. But if they were burning for the science, then they would work all night, you know [laughs]. (Sophia, group leader)

She stated further that the students' excitement would lead to spin-off projects in which they would produce data for potential papers and work on their own reputation as scientists. As a group leader, Sophia profits from such behaviour as it might result in good publications and meet her aim to 'produce quality people that go out into the world'. Moreover, the 'burning' was often based on the group leaders' or senior postdocs' own experiences in which they immersed themselves into science and were 'all in' (Jonas, department leader). And while recalling their past experience in the lab, the scientists frequently bemoaned a lack of commitment and devotion in the younger generation. Consequently, I depict passion as becoming constitutive for a hard-working ethos of an excited scientist.

In addition to searching for students who would show a passionate relationship with scientific work, some group leaders and senior postdocs were concerned with how to select the most dedicated students. For example, Sophia, a group leader, was concerned with education quality and how students could be chosen on the basis of specific criteria. According to her, a screening mechanism similar to the European master's system would be worthwhile to 'see "is this really what you want to do or not?"' A mandatory master's programme and figuring out what you 'love' and need in order to be happy were common imaginations for a better method of student selection. By saying that 'not every person should get a PhD just because a person 
starts on (a career) track', Sophia is in company with others who declare that: 'It is not for everyone, obviously' (Abigail, postdoc). Some scientists would be good at analytical thinking, while others would either not be 'trained' properly or lack 'the natural ability to analyse what they see' (Abigail, postdoc). Furthermore, Abigail declared this path as not possible for everyone due to long work hours and time periods in which frustration would outweigh positive results. Hence, I find the imaginations of group leaders and senior postdocs about potential future students as closely entwined with how they envision selection criteria.

The researchers claim that the future generation needs to show excitement for and dedication to the job. Related to this are expectations assuring that these students have what it takes to accomplish a scientific career, such as enthusiasm about work and life in the laboratory and the willingness to work all night. Group leaders and senior postdocs also described a specific time when young academics would need to demonstrate this emotional trait. They positioned the younger generation as in need of working in a similar fashion and emotional state as they did during their own time in the lab. Formulating a prospective vision implies potential for selection, as the group leaders and postdocs envisioned possible qualifying gates for students that would make it easier to decide if a student would be dedicated to scientific work and if science would be something the students would like to do. Hence, while the narration of the group leaders' and senior postdocs' own past experiences signifies continuity in their life, which is 'tied to envisioned futures, or constructed retrospectively, as past events gain coherence and purpose through narrative' (Garforth and Červinková 2009, p. 175), the tales also imply an imagination of a future generation of scientists. This imagination creates a condition in which young scientists are urged to adapt to a powerful ideal — a condition that allows for a self-regime in which scientists are individually responsible for managing their emotional relationship with the profession.

\subsection{Conclusions}

In this chapter, I have shown that emotional relationships of scientists with their profession are having an impact on their self-perception and identity construction. As the scientists talk about their individual emotional states of being, they not only construct their career stage-dependent identities as researchers but also reinforce a quasi-romantic ideal of how researchers need to think and feel about a life in science according to a particular emotional scheme. In line with this, passionate tales provide some order in and for scientific communities and show that the scientists' emotional relationship with their profession is key to understanding the construction of their identities.

As the scientists narrated their passion-'drive'-for the profession, I have shown first that the group leaders and postdocs revisited their time of initiation and narrated their scientific self by invoking a past in which they had discovered 
their initial fascination with science as subject and practice. Second, when reflecting back on their early career phases, the scientists showed their commitment to their work by describing the spatial and temporal concessions they were willing to make and that have formed their self-understanding ever since. Finally, I have depicted which characteristics group leaders and senior postdocs looked for in the younger generation as they positioned the future generation by drawing on their own pasts in science. These stories not only inherit a quasi-nostalgic memory of the past (Holden 2015) but also comprise a passionate tale in which the scientists build on their 'drive', such as by remembering their initial fascination, enthusiasm, and commitment towards science. Being a scientist, then, means to be passionately driven and to demonstrate this in specific ways in the respective career stages.

I derive two main conclusions from these analyses: first, passionate tales provide order for the scientific community as they build an imaginative ideal of a passionate scientist through emotional schemes and behavioural patterns; second, the narratives provide the scientists with continuity by constructing an emotional track record.

Passionate tales about the past declare characteristics of a 'good scientist' (Traweek 1988) as they (re-)construct an ideal in which the fate of a scientist's soul depends on her/his work (Weber 1918/1946). And although the imagination of passion might not deviate much in its characteristics from that proposed a hundred years ago, it represents a cultural stability for science communities that are otherwise subject to change. It is crucial to note that the scientists' narratives were all similar to each other and lacked multiplicity in their storylines. Accordingly, these stories also imply marginalisation. This is evident, for example, when a scientist does not make use of the right timing to develop a career, such as when having a family and not being able to work all night, or in deciding that one does not want to pursue tenure but rather get a more stable position. Although such alternative ways of living a life in science exist, they are not dominant in the conceptualisation of a scientific identity. When the biologists refer to their shortcomings as not-ideal scientists, they support and manifest a norm of the hardworking, committed academic who is dedicated to scientific concerns, expanding the unknown frontier, and caring for the scientific community. In this sense, I argue that passionate tales also demarcate a regime of selection.

Scientists need to constantly demonstrate passion in order to correspond to an ideal imagination of a scientist. They need to work as experts of their emotions and their skills (Rose 1996). This is the case, for example, when researchers imagine a future generation working in accordance with temporal and spatial requirements. Yet, only those who conform to the demands of the profession can be scientists. Passion provides distinctiveness for those who are scientists and is recounted as intrinsic to everyone who becomes a scientist in the early career phase. While this brings forth an exclusive identity nourished by tales of the past and embedded in a common emotional culture, this also means that scientists have to work continuously towards an ideal that disciplines them into a 'neoliberal regime with ever-growing costs', not least to themselves (Gill 2010, p. 241).

Aside from creating selection criteria, I state that passionate tales introduce a profound stability for the scientists. The proposed stability is based on the storyline 
that the scientists create and that — at least temporarily-merges the initial detection of ones' interest, the early career stage, and the present. The group leaders and postdocs reflexively create a 'plot' in their lives that corresponds with their identity as passionate scientists. This plot also provides for consistency in their lives, as they have been and always will be passionate scientists. While this is an expression of their emotional relationship with the profession, their love and affection for what they do, it is also a sign of the inevitable need to embed one's identity in a temporary stable framing while committing to the demands of a life in science.

This stability is of high importance given the instabilities and insecurities that pervade work in the biosciences. These resemble the tenuous working conditions on a societal level outside academia. Work has transformed from a 'vocation or a life's mission' into a notion that is much more 'fragile and friable' (Bauman 2001, p. 45) with a regime of short-term work permeating today's society in which identity work is never stable and fixed, always appearing open and unfinished (Keupp 1994). This ephemeral nature of inhabited positions is significant for today's society-and for academia in particular - as traditional and contemporary ideals merge in researchers' narratives (Felt and Stöckelova 2009). In line with merging traditional and contemporary ideals is a passionate self that creates consistency in scientific communities and a steady reference frame for the scientists' identity construction and performance.

To conclude, focussing on scientists' pasts allows for a profound analysis of the imagined appropriate characteristics for a life in science. As scientists continuously produce and reproduce an imagination of passion while building on their own past in science, they create selection criteria for those to come. For instance, they determine that passion is mandatory in order to become a successful researcher. As such, passionate tales serve to seduce the scientists into a romantic logic while also underpinning a neoliberal regime in which scientists have to show extensive commitment. Aside from creating individual stability in the scientists' lives, such tales also seem to produce a normative ideal that promotes scientists who are fully committed through an emotional relationship to their profession and work. Passionate tales thereby nourish a self-regime that focusses on individual capabilities for managing behaviour as well as emotional responses. This condition raises urgent questions such as: who is able to conform to a powerful ideal of a passionate scientist and who is not? How does a self-regime that centres on the individual and her/his ability to manage an emotional relationship with the profession possibly change a future generation of scientists?

Based on these questions, I argue that there is an urgent need to trace stories that are different, those that resist a normative ideal. And we as academics need to take a critical stance on what 'passionate work' in the sciences means and how identity at work can be built and criticised. Only then can scientific identities be reflected upon in ways that do not disguise alternative forms but open up multiple possibilities for stories to be told.

Acknowledgements First of all, I would like to thank the biologists who generously agreed to talk to me and shared their stories. I would like to thank the editors of this volume, Susan 
Molyneux-Hodgson and Karen Kastenhofer, for their continuous help with and care for this chapter. Many thanks are due to the reviewers for their constructive comments and help in re-writing this chapter. I would also like to thank Ulrike Felt for sharing her worthwhile comments when I first presented this work at the STS Austria workshop on 'Identity and Community' in February 2017 and Niki Vermeulen for her invaluable feedback on the manuscript. And finally, I would like to thank the University of Vienna for supporting me in the time of writing this chapter with a Dissertation Completion Fellowship.

\section{References}

Acker, J. 1990. Hierarchies, jobs, bodies: A theory of gendered organizations. Gender \& Society 4 (2): 139-158.

Barbalet, J. 2002. Science and emotions. The Sociological Review 50 (S2): 132-150.

Bauman, Z. 2001. Community: Seeking safety in an insecure world. Oxford: Blackwell Publishers. Beaufaÿs, S. 2003. Wie werden Wissenschaftler gemacht? Bielefeld: Transcript.

- 2015. Die Freiheit arbeiten zu dürfen. Akademische Laufbahn und legitime Lebenspraxis. Beiträge zur Hochschulforschung 37 (3): 40-58.

Cech, E.A., and M. Blair-Loy. 2014. Consequences of flexibility stigma among academic scientists and engineers. Work and Occupations 41 (1): 86-110.

Charmaz, K. 2006. Constructing grounded theory. London: Sage.

Collins, R. 1998. The sociology of philosophies. Cambridge, MA: Harvard University Press.

Csikszentmihalyi, M. 1996. Creativity: Flow and the psychology of discovery and invention. New York: Harper Perennial.

Daston, L. 2003. Die wissenschaftliche Persona. Arbeit und Berufung. In Zwischen Vorderbühne und Hinterbühne: Beiträge zum Wandel der Geschlechterbeziehungen in der Wissenschaft vom 17. Jahrhundert bis zur Gegenwart, ed. T. Wobbe, 109-136. Transcript: Bielefeld.

Felt, U., and T. Stöckelova. 2009. Modes of ordering and boundaries that matter in academic knowledge production. In Knowing and living in academic research. Convergence and heterogeneity in research cultures in the European context, ed. U. Felt, 41-124. Prague: Institute of Sociology of the Academy of Sciences of the Czech Republic.

Fitzgerald, D. 2013. The affective labour of autism neuroscience: Entangling emotions, thoughts and feelings in a scientific research practice. Subjectivity 6 (2): 131-152.

Garforth, L., and A. Červinková. 2009. Times and trajectories in academic knowledge production. In Knowing and living in academic research. Convergence and heterogeneity in research cultures in the European context, ed. U. Felt, 169-226. Prague: Institute of Sociology of the Academy of Sciences of the Czech Republic.

Giddens, A. 1991. Modernity and self-identity: Self and society in the late modern age. Cambridge: Polity Press and Blackwell Publishing Ltd.

Gill, R. 2010. Breaking the silence: The hidden injuries of neo-liberal academia. In Secrecy and silence in the research process: Feminist reflections, ed. R. Flood and R.C. Gill, 228-244. New York: Routledge.

Hackett, E.J. 1990. Science as a vocation in the 1990s: The changing organizational culture of academic science. The Journal of Higher Education 61 (3): 241-279.

Hakala, J. 2009. The future of the academic calling? Junior researchers in the entrepreneurial university. Higher Education 57 (2): 173.

Holden, K. 2015. Lamenting the golden age: Love, labour and loss in the collective memory of scientists. Science as Culture 24 (1): 24-45.

Kerr, A., and D. Lorenz-Meyer. 2009. Working together apart. In Knowing and living in academic research. Convergence and heterogeneity in research cultures in the European context, ed. U. Felt, 127-167. Prague: Institute of Sociology of the Academy of Sciences of the Czech Republic. 
Keupp, H. 1994. Ambivalenzen postmoderner Identität. In Riskante Freiheiten. Individualisierung in modernen Gesellschaften, ed. U. Beck and E. Beck-Gernsheim, 336-350. Frankfurt am Main: Suhrkamp.

Koppman, S., C.L. Cain, and E. Leahey. 2015. The joy of science: Disciplinary diversity in emotional accounts. Science, Technology, \& Human Values 40 (1): 30-70.

Laufenberg, M., M. Erlemann, M. Norkus, and G. Petschick. 2018. Prekäre Gleichstellung - Eine Einleitung. In Prekäre Gleichstellung, 1-24. Wiesbaden: Springer.

Law, J. 1994. Organizing modernity. Oxford: Blackwell Publishers.

McRobbie, A. 2004. Making a living in London's small-scale creative sector. In Cultural industries and the production of culture, ed. D. Power and A.J. Scott, 130-144. London: Psychology Press.

Merton, R.K. 1973. The sociology of science: Theoretical and empirical investigations. Chicago: University of Chicago Press.

Mitroff, I.I. 1974. Norms and counter-norms in a selected group of Apollo moon scientists: A case study in the ambivalence of scientists. American Sociological Review 39: 579-595.

Mumby, D.K. 1987. The political function of narrative in organizations. Communications Monographs 54 (2): 113-127.

Neumann, A. 2006. Professing passion: Emotion in the scholarship of professors at research universities. American Educational Research Journal 43 (3): 381-424.

Parker, J.N., and E.J. Hackett. 2012. Hot spots and hot moments in scientific collaborations and social movements. American Sociological Review 77 (1): 21-44.

- 2014. The sociology of science and emotions. In Handbook of the Sociology of emotions: Volume II, ed. J.E. Stets and J.H. Turner. Springer.

Pickersgill, M. 2012. The co-production of science, ethics, and emotion. Science, Technology, \& Human Values 37 (6): 579-603.

Ricoeur, P. 1980. Narrative time. Critical Inquiry 7 (1): 169-190.

Rose, N. 1996. Inventing ourselves. Psychology, power and regulation. London: Sage.

Schönbauer, S. 2018. We are standing together in front. How scientists and research groups form identities in the life sciences. Science \& Technology Studies: 1-21.

Sigl, L. 2016. On the tacit governance of research by uncertainty. How early stage researchers contribute to the governance of life science research. Science, Technology \& Human Values 41: 347-374.

Slaughter, S., and L.L. Leslie. 1999. Academic capitalism. In Politics, policies, and the entrepreneurial university. Baltimore: Johns Hopkins University Press.

Traweek, S. 1988. Beamtimes and lifetimes. Cambridge: Harvard University Press.

Weber, M. 1930. The Protestant ethic and the spirit of capitalism. London: Allen \& Unwin. (Original work published 1905).

. 1946. Science as a vocation. In From Max Weber: Essays in sociology, ed. H. Gerth and C.W. Mills, 129-158. New York: Oxford. (Original work published 1918).

Ylijoki, O., and J. Ursin. 2015. High-flyers and underdogs: The polarisation of Finnish academic identities. In Academic identities in higher education: The changing European landscape, ed. L. Evans and J. Nixon, 187-202. London: Bloomsbury Academic. 
Open Access This chapter is licensed under the terms of the Creative Commons Attribution 4.0 International License (http://creativecommons.org/licenses/by/4.0/), which permits use, sharing, adaptation, distribution and reproduction in any medium or format, as long as you give appropriate credit to the original author(s) and the source, provide a link to the Creative Commons license and indicate if changes were made.

The images or other third party material in this chapter are included in the chapter's Creative Commons license, unless indicated otherwise in a credit line to the material. If material is not included in the chapter's Creative Commons license and your intended use is not permitted by statutory regulation or exceeds the permitted use, you will need to obtain permission directly from the copyright holder. 